\title{
Accuracy of patient-reported height loss and risk factors for height loss among postmenopausal women
}

\author{
Karine Briot MD PhD, Erik Legrand MD PhD, Denis Pouchain MD, Stéphanie Monnier PhD, \\ Christian Roux MD PhD
}

Previously published at www.cmaj.ca

\section{ABSTRACT}

Background: Since loss of height may indicate vertebral fracture, the accuracy of the information on height is relevant for clinical practice. We undertook this study to compare reported and measured loss of height among postmenopausal women in a primary care setting. We also analyzed the determinants of this height loss.

Methods: In an observational study conducted between December 2007 and May 2008, we asked 1779 randomly selected general practitioners to recruit the first five female patients who were more than 60 years of age, regardless of the reason for the consultation. Using a questionnaire, physicians collected data on demographic and clinical variables, history of osteoporosis and current antiosteoporotic treatment. We used three assessments of height: tallest height in early adulthood recalled by the patient, estimated current height reported by the patient at the visit and current measured height. We defined loss of height as the difference between the patient's tallest recalled height and her current measured height.

Results: A total of 8610 patients were included in the analysis; the mean age was 70.9 (standard deviation [SD] 7.2) years. The mean loss of height was $4.5 \mathrm{~cm}$. The mean current reported height was 2.1 (SD 2.5) $\mathrm{cm}$ lower than the tallest recalled height and $2.4(\mathrm{SD} 2.6) \mathrm{cm}$ lower than the measured current height. The best predictors of a loss of height of $3 \mathrm{~cm}$ or more were age (odds ratio [OR] 1.09, $95 \%$ confidence interval $[\mathrm{Cl}] 1.08-1.10)$, previous vertebral fracture (OR 1.49, 95\% Cl 1.16-1.91), previous nonvertebral fracture (OR 1.26, 95\% Cl 1.06-1.51), thoracic kyphosis (OR 2.07, 95\% Cl 1.69-2.55), scoliosis (OR 1.35, 95\% Cl 1.12-1.63), back pain (OR 1.22, 95\% Cl 1.07-1.39) and osteoporosis (OR 1.39, 95\% Cl 1.20-1.60).

Interpretation: Our study showed that the patients' estimated current height was not correct, with a mean difference of $-2.5 \mathrm{~cm}$ from the current measured height. The mean height loss was $4.5 \mathrm{~cm}$. Previous vertebral fracture and thoracic kyphosis were strong determinants of the height loss. oss of height is common with advancing age. ${ }^{1,2}$ Causes include changes in curvature of the spine, narrowing of intervertebral discs and vertebral fractures. Height loss is associated with back pain and thoracic hyperkyphosis. ${ }^{3,4}$ Two-thirds of adults have back pain at any time. Controversies exist about the need for radiographs of the spine: Does the benefit of detecting treatable disorders of the spine such as vertebral fracture outweigh the harm of unnecessary radiographs? Loss of height is usually recorded as one of the clinical signs to help identify postmenopausal women with vertebral fractures. ${ }^{5}$ The use of this parameter to decide whether radiography is needed depends on the threshold for height loss associated with a strong risk of vertebral fracture. The thresholds useful in clinical practice to detect prevalent vertebral fracture range from $3 \mathrm{~cm}$ to $6 \mathrm{~cm},{ }^{6-9}$ with the risk of prevalent fracture increasing with the magnitude of the height loss. Thus, the accuracy of the information on height is relevant for clinical practice.

We conducted this study to compare reported and measured loss of height in a large population of women more than 60 years old in a primary care setting and to analyze the determinants of this height loss.

\section{Methods}

\section{Study design}

We conducted a multicentred observational study between December 2007 and May 2008 at primary care practices in France. We randomly selected general practitioners from a national representative database. To be eligible, physicians had to have a large practice that included women more than 60 years old. We estimated that the sample would need to include at least 3500 general practitioners. We selected 3621 general practitioners and contacted them by phone; 1779 agreed to participate (Figure 1).

The general practitioners were asked to recruit the first five female patients who were more than 60 years of age, regardless of the reason for the consultation. During the visit, the physicians completed a questionnaire with the following information: patient's age, weight, start of menopause, history of fracture after age 45 years, history of spinal disease such as osteoarthritis, history of back pain, past or current intake or corticosteroids for

From the Department of Rheumatology (Briot, Roux), Hôpital Cochin and Université Paris Descartes, Paris, France; the Department of Rheumatology (Legrand), Université d'Angers, Angers, France; the Department of General Practice (Pouchain), UFR de Médecine Paris-lle-de-France Ouest, Paris, France; and ABR Pharma (Monnier), Paris, France

CMAJ 2010. DOI:10.1503/cmaj.090710 
three or more months, history of osteoporosis and current use of anti-osteoporosis treatment. They checked the patients' charts to see whether bone densitometry had been performed; the diagnosis of osteoporosis was defined by a T score of -2.5 or less.

The physicians were also asked to review the recruited patients' files to see if they had had any radiographs of the spine performed. They checked the radiographs or the radiologists' reports in the files for data on the presence or absence of vertebral fractures, scoliosis, thoracic kyphosis or osteoarthritis of the spine.

\section{Measurement of loss of height}

We used three assessments of height in this study: tallest recalled height, current reported height and current measured height. The tallest recalled height was obtained using either the height recorded on documentation (passport, national identity card) between 20 and 50 years of age or the tallest height at 20 years of age recalled by the patient.

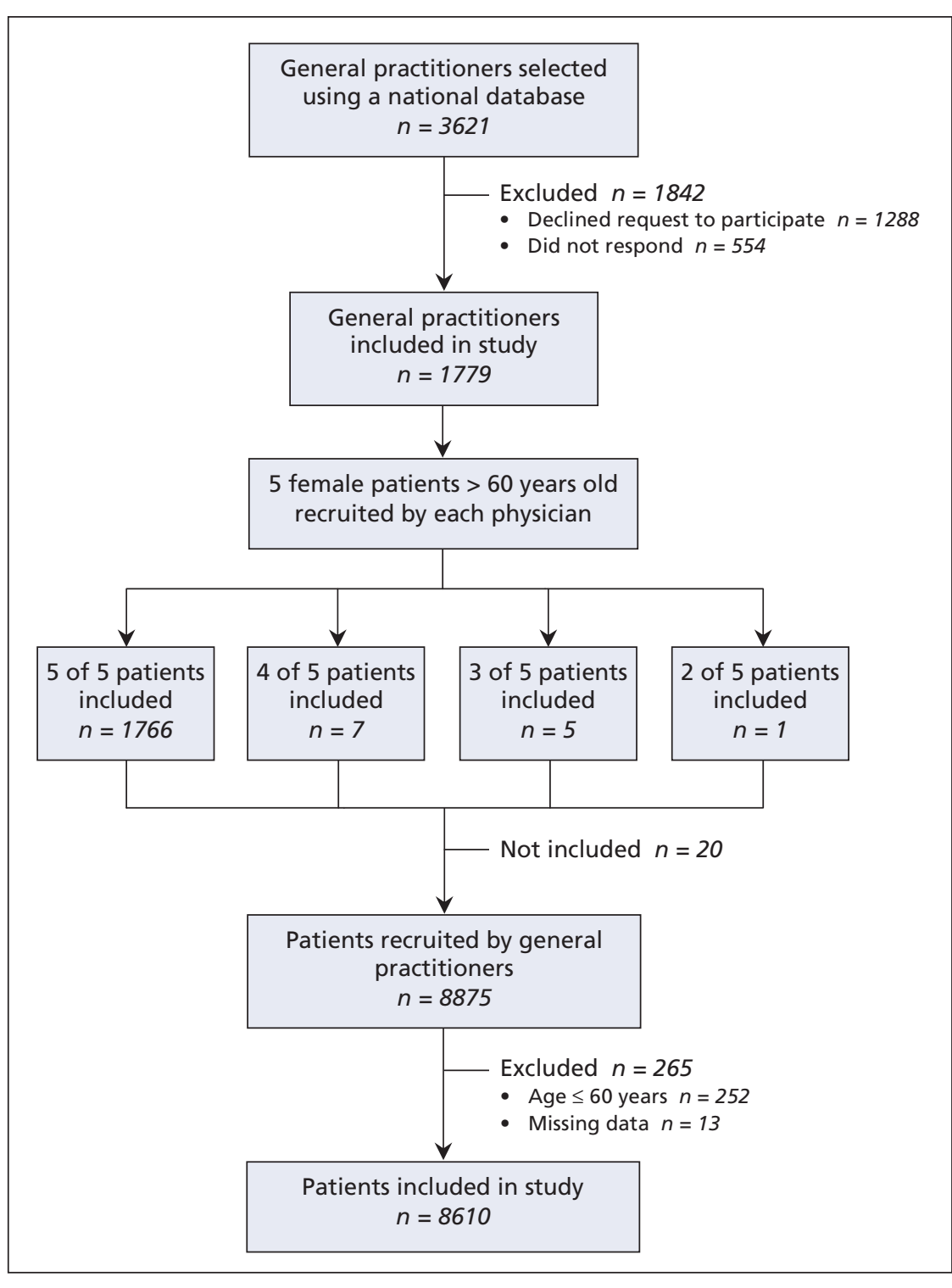

Figure 1: Recruitment of the general practitioners and patients.
Current reported height was the estimated current height reported by the patient at the visit before any measurement.

Current measured height was measured with the use of an electronic stadiometer. Each patient was measured without shoes, with her heels, buttocks and back to the stadiometer backboard. The patient's head was maintained in the Frankfort plane, with the lower edge of the left eye socket in the same horizontal plane as the notch superior to the tragus of the left ear. ${ }^{10,11}$ The patient was instructed to stretch to a fully erect position while keeping her feet flat on the floor. Height was recorded to the closest millimetre during normal respiration. $^{10,11}$ Three consecutive measurements were obtained, and the mean was recorded.

\section{Statistical analysis}

We used means and standard deviations (SDs) for continuous variables and percentage distributions for discrete variables. Means were compared with use of the Mann-Whitney and Kruskal-Wallis tests. Loss of height was defined as the difference between the patient's tallest recalled height and the current measured height.

We performed logistic regression analysis to determine predictive factors of height loss among patients who had a loss of height of at least $3 \mathrm{~cm}(\mathrm{v} .<3 \mathrm{~cm})$ and among those who had a loss of height of at least $6 \mathrm{~cm}$ (v. $<6 \mathrm{~cm})$. As an exploratory analysis, we used information from the radiologists' reports, where available in the women's files, to study the relation between height loss and risk of vertebral fracture. We performed sensitivity and specificity analyses to determine the threshold for height loss to use in the multivariable analysis.

\section{Results}

\section{Patient characteristics}

A total of 8875 postmenopausal women were recruited by the general practitioners; we excluded $265(3.0 \%)$ of them because of missing data concerning their age or because they were 60 years of age or younger.

The baseline characteristics of the remaining 8610 women are reported in Table 1. Overall, 2391 (27.8\%) of the patients reported a history of clinical fracture after age 45 years (13.1\% reported a wrist fracture, $9.2 \%$ a vertebral fracture, $2.3 \%$ a hip fracture and $7.4 \%$ another"other" fracture). Of the 4238 patients who had undergone bone densitometry, 1938 (45.7\%) had osteoporosis. Overall, 2936 (34.1\%) of the 8610 patients were receiving at least one anti-osteoporosis agent (bisphosphonate, parathyroid hormone, selective estrogen 
receptor modulator or strontium ranelate); this proportion was $38.3 \%$ ( $n=1609)$ among the 4201 women who were more than 70 years old.

Radiographs of the spine were available in the files of 5179 $(60.2 \%)$ of the recruited patients. They were performed within one year before the visit for $1819(35.1 \%)$ and more than one year before the visit for $3360(64.9 \%)$. The radiograph or radiologist's report showed clinical vertebral fracture in $12.7 \%$ (973/7683) patients, scoliosis in $23.1 \%$ (1753/7604), thoracic kyphosis in $24.2 \%(1836 / 7582)$ and osteoarthritis of the spine in $50.9 \%(3835 / 7534)$.

\section{Height loss}

The different height values are presented in Table 2. The tallest recalled height was estimated at the mean age of 20.7 (SD 4.0) years, on the basis of documentation (passports, identity card) in $4.4 \%$ and the patient's memory of height attained in young adulthood in $95.6 \%$. The mean estimated current height reported by the women the day of the visit was significantly lower than the mean tallest recalled height at age 20 (difference -2.1 [SD 2.5] cm) and the mean measured height (difference -2.4 [SD 2.6] cm) (Table 2).

The mean height lost was 4.5 (SD 3.0) cm. Overall, 165 (2.0\%) of the patients did not lose any height, 5843 (70.9\%) had a loss of at least $3 \mathrm{~cm}$, and $2239(27.1 \%)$ had a loss of at least $6 \mathrm{~cm}$; the remaining 363 patients had a loss of less than $3 \mathrm{~cm}$.

The mean loss of height was $4.8 \mathrm{~cm}$ (SD 3.0) among the patients who were taking anti-osteoporosis treatment and $4.3 \mathrm{~cm}$ (SD 2.9) among those not taking such treatment $(p<0.001)$.

Table 1: Characteristics of 8610 female patients more than 60 years of age who were included in the study

\begin{tabular}{|c|c|}
\hline Characteristic & Value \\
\hline Age, yr, mean (SD) & $70.9(7.2)$ \\
\hline Age at start of menopause, yr, mean (SD) & $50.0 \quad(4.2)$ \\
\hline Weight, kg, mean (SD) & $65.8(11.9)$ \\
\hline Body mass index, mean (SD) & $26.6(4.7)$ \\
\hline $\begin{array}{l}\text { Previous or current use of corticosteroids } \\
\text { for } \geq 3 \mathrm{mo}, \% \text { (no.) }\end{array}$ & $5.3(446 / 8483)$ \\
\hline $\begin{array}{l}\text { History of clinical fracture after age } \\
45 \text { years, \% (no.) }\end{array}$ & $27.8(2391 / 8610)$ \\
\hline Wrist & $13.1(1129 / 8610)$ \\
\hline Vertebra & $9.2(796 / 8610)$ \\
\hline Hip & $2.3(200 / 8610)$ \\
\hline Other & $7.4(634 / 8610)$ \\
\hline \multicolumn{2}{|l|}{ Finding on radiograph, \% (no.) } \\
\hline Vertebral fracture & $12.7(973 / 7683)$ \\
\hline Scoliosis & $23.1(1753 / 7604)$ \\
\hline Thoracic kyphosis & $24.2(1836 / 7582)$ \\
\hline Osteoporosis, * \% (no.) & $45.7(1938 / 4238)$ \\
\hline$\geq 1$ anti-osteoporosis agent, $\uparrow \%$ (no.) & $34.1(2936 / 8610)$ \\
\hline
\end{tabular}

Note: $\mathrm{SD}=$ standard deviation.

*T score $\leq-2.5$.

†Bisphosphonate, parathyroid hormone, selective estrogen receptor modulator or strontium ranelate.

\section{Determinants of height loss}

The multivariable analysis showed that the best predictors of a loss of height of $3 \mathrm{~cm}$ or more were age, previous vertebral fracture, previous nonvertebral fracture, thoracic kyphosis, scoliosis, back pain and osteoporosis. The best determinants of a loss of $6 \mathrm{~cm}$ or more were age, previous vertebral fracture, previous nonvertebral fracture, thoracic kyphosis and scoliosis (Table 3).

\section{Relation between height loss and vertebral fracture}

Of the 6713 patients whose general practitioner could determine the presence or absence of a vertebral fracture from the radiograph or radiologic report, $973(14.5 \%)$ had a vertebral fracture. Compared with patients who did not have a vertebral fracture, those who did were significantly older (mean 74.4 [SD 7.4] v. 70.2 [SD 6.9] years), shorter (mean 155.9 [SD 7.1] v. 157.8 [SD 6.3] cm), thinner (mean 63.1 [SD 11.3] v. 66.1 [SD 11.8] kg) and lost more height (mean 6.1 [SD 3.4] v. 4.3 [SD 2.8] cm) $(p<0.001$ for each comparison). They reported current use of corticosteroids, osteoporosis and previous nonvertebral fracture more often than the women without vertebral fractures. With respect to the presence of vertebral fracture on the radiologist's report, a threshold of $4 \mathrm{~cm}$ of height loss had a sensitivity of $74 \%$ and a specificity of $49 \%$; a threshold of $6 \mathrm{~cm}$ had a sensitivity of $47 \%$ and a specificity of $76 \%$ (Figure 2). Multivariable analysis using a threshold of height loss of at least $4 \mathrm{~cm}$ showed that the best predictors of the presence of vertebral fracture were age, a history of height loss of at least $4 \mathrm{~cm}$, back pain and previous nonvertebral fracture.

\section{Interpretation}

We observed a mean loss of height of $4.5 \mathrm{~cm}$ since early adulthood in a large population of postmenopausal women in primary care practices. The patient's estimated current height was not a correct assessment of this parameter. There was a significant difference $(-2.1 \mathrm{~cm})$ between the current height reported by the women during the visit and their tallest recalled height at age 20. Despite this "pessimistic" view, the estimated current height was wrong, with the measured height being actually $2.4 \mathrm{~cm}$ lower. The prevalence of vertebral fractures on radiologic reports was $12.7 \%$. We found that the risk of existing vertebral fracture was significantly higher among

Table 2: Measurements of height

\begin{tabular}{lr}
\hline Variable & Mean (SD) \\
\hline Age at tallest recalled height, yr & $20.7(4.0)$ \\
\hline Age at visit, yr & $70.9(7.2)$ \\
\hline Tallest recalled height, cm & $162.0(5.9)$ \\
Current height reported by patient, cm & $160.0(6.1)$ \\
Current measured height, cm & $157.5(6.5)$ \\
\hline Height lost, ${ }^{*} \mathrm{~cm}$ & $4.5(3.0)$ \\
\hline
\end{tabular}

Note: $\mathrm{SD}=$ standard deviation

* Loss of height was defined as the difference between the patient's tallest recalled height and the current measured height. 
patients with a height loss of at least $4 \mathrm{~cm}$, a threshold similar to the one recommended by the International Society for Clinical Densitometry. ${ }^{7}$

Previous studies have shown that patients' estimated current and recalled heights tend to be higher than measured heights and that the tallest recalled height may be overestimated. ${ }^{12,13}$ Overestimated height increased with age, occurring in $70 \%$ of those aged 80 and older. Compared with people with normal bone density, a significantly higher proportion of men with osteoporosis $(76 \%$ v. $47 \%, p<0.001)$ and women with osteoporosis $(52 \%$ v. $35 \%, p<0.001)$ overestimated their height. In addition, significant misclassification of selfreported height and weight occurred among people in poor health and those with poor performances on memory and calculation tests. ${ }^{14,15}$ However, previous studies did not show that the reported current height was lower than the tallest recalled height. Our finding of a difference of $-2.1 \mathrm{~cm}$ between these values was surprising, because the patients had just given their tallest recalled height. A previous study showed that women who consulted in primary health care increased the severity of their complaint and had a pessimistic appraisal of their health. ${ }^{16}$

Loss of height may occur for several reasons, such as postural change, degenerative intervertebral disc disease or vertebral fracture. In a population-based study of the incidence of clinical vertebral fracture, only $30 \%$ of women who had a vertebral fracture visited a health care provider with symptomatic complaints. ${ }^{17}$ Measurement of height loss could be an accurate method for detecting prevalent vertebral fractures; however, there are discrepancies concerning the relevant threshold for height loss. ${ }^{18,19}$ In a study involving 322 postmenopausal women with osteoporosis, Siminosky and colleagues showed that a loss of height greater than $6.0 \mathrm{~cm}$ rules in prevalent vertebral fracture and proposed that patients with a loss of at least $6 \mathrm{~cm}$ should have a radiograph taken. ${ }^{9}$ In a population-based, retrospective study, Gunnes and colleagues found that the risk of vertebral fracture increased about five-

\begin{tabular}{|c|c|c|}
\hline \multirow[b]{2}{*}{ Variable } & \multicolumn{2}{|c|}{ Loss of height; adjusted OR* (Cl 95\%) } \\
\hline & $\geq 3 \mathrm{~cm}$ & $\geq 6 \mathrm{~cm}$ \\
\hline Age at visit & $1.09(1.08-1.10)$ & $1.09(1.08-1.10)$ \\
\hline $\begin{array}{l}\text { Age at start of } \\
\text { menopause }\end{array}$ & $0.98(0.97-1.00)$ & - \\
\hline Back pain & $1.22(1.07-1.39)$ & - \\
\hline $\begin{array}{l}\text { Previous vertebral } \\
\text { fracture }\end{array}$ & $1.49(1.16-1.91)$ & $1.80(1.49-2.19)$ \\
\hline $\begin{array}{l}\text { Previous clinical } \\
\text { fracture }\end{array}$ & $1.26(1.06-1.51)$ & $1.13(1.49-2.19)$ \\
\hline Scoliosis & $1.35(1.12-1.63)$ & $1.15(0.94-1.39)$ \\
\hline Thoracic kyphosis & $2.07(1.69-2.55)$ & $1.90(1.60-2.27)$ \\
\hline Osteoporosist & $1.39(1.20-1.60)$ & - \\
\hline
\end{tabular}

Note : $\mathrm{Cl}=$ confidence interval, $\mathrm{OR}=$ odds ratio.

*Each variable was adjusted for the other variables in the table.

†T score $\leq-2.5$.

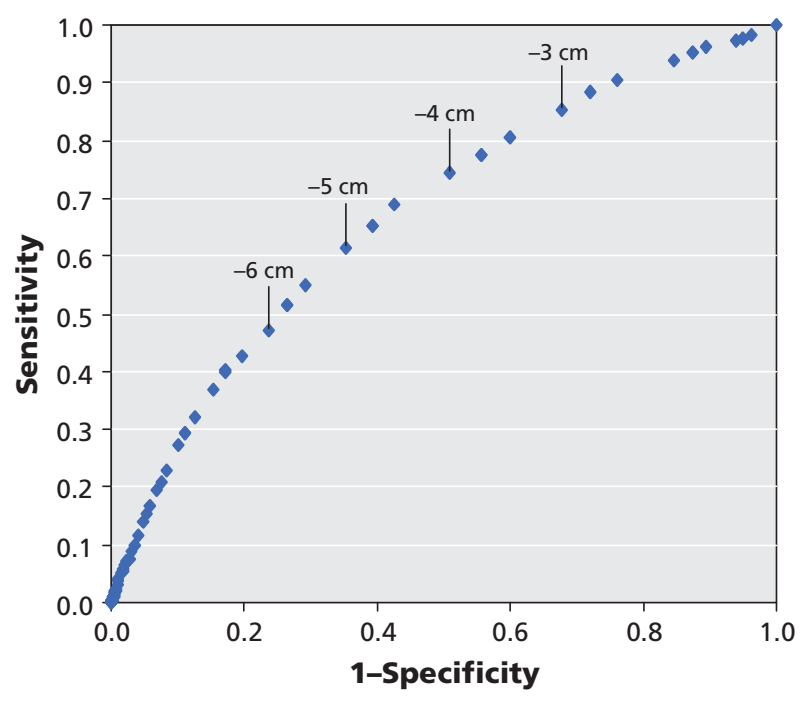

Figure 2: Sensitivity and specificity analysis (receiver operating characteristics curve) of the relation between loss of height and presence of vertebral fracture on the radiologic report.

fold among women who had a loss of at least $3 \mathrm{~cm}$ in height compared with those who had maintained height. ${ }^{6}$

The differences in thresholds may be explained by the differences in the patients' characteristics and the type of recruitment (primary care setting or not). The high prevalence of height loss in our study population contrasts with the low prevalence of vertebral fracture, which suggests that height loss is not fully explained by the presence of vertebral fractures. Siminovski and colleagues showed that the average height loss per vertebral fracture is $0.97 \mathrm{~cm},{ }^{9}$ which suggests that height loss is linked not only to vertebral fractures. In our study, age, thoracic kyphosis and scoliosis were other strong determinants of height loss.

\section{Limitations}

Our study had several limitations. Although it was performed in a nonspecialist setting and involved women who were not referred for osteoporosis assessment, the proportion of patients who had osteoporosis or were taking anti-osteoporosis treatment was higher than expected. We can hypothesize that only general practitioners most interested in osteoporosis agreed to participate or that, by knowing the purpose of the study, the physicians preferentially included patients with osteoporosis. Prevalent vertebral fractures were assessed by the general practitioners after reviewing the radiographs or radiologic reports, and we were unable to confirm the diagnosis of fractures. It has been shown that up to $20 \%$ of fractures may not be recognized, in part because of an ambiguous radiologic report. ${ }^{20}$ With the proportion of missing data at less than 5\%, we considered that our choice of method would not significantly alter the results.

\section{Conclusion}

In this observational study involving a large population of postmenopausal women more than 60 years old, we observed 
that the estimated current height reported by the women was incorrect, with a mean difference of $-2.4 \mathrm{~cm}$ from the current measured height. Thus, general practitioners need to measure the height of their postmenopausal patients and not rely on reported estimates. Previous vertebral fracture and thoracic kyphosis were strong determinants of the height loss.

This article has been peer reviewed.

Competing interests: Christian Roux and Erik Legrand received honoraria from Merck for participating in this study. No competing interests declared by Karine Briot, Denis Pouchain or Stéphanie Monnier. Stéphanie Monnier is employed at ABR Pharma, the contract research organization in charge of the implementation and operational follow-up of the study, the data management and the statistical analysis.

Contributors: Christian Roux, Erik Legrand and Denis Pouchain contributed to the study concept and design. Stéphanie Monnier was involved in the collection and assembly of data. All of the authors contributed to the analysis and interpretation of data. Karine Briot and Christian Roux drafted the manuscript. All of the authors revised the manuscript for important intellectual content and approved the final version submitted for publication.

Funding: This study was conducted with an unrestricted grant from Merck. Merck had no role in the design of the study, the collection, analysis or interpretation of data, the writing of the report or the decision to submit the article for publication.

\section{REFERENCES}

1. Kado DM, Huang MH, Karlamangla AS, et al. Hyperkyphotic posture predicts mortality in older community-dwelling men and women: a prospective study. $\mathrm{J} \mathrm{Am}$ Geriatr Soc 2004:52:1662-7.

2. Takahashi T, Ishida K, Hirose D, et al. Trunk deformity is associated with a reduction in outdoor activities of daily living and life satisfaction in community-dwelling older people. Osteoporos Int 2005;16:273-9.

3. Roux C, Briot K, Kolta S, et al. Thoracic kyphosis index as a risk factor for incident vertebral fractures and alteration of quality of life in postmenopausal women with osteoporosis. J Bone Miner Res 2009;S38.

4. Spector TD, McCloskey EV, Doyle DV, et al. Prevalence of vertebral fracture in women and the relationship with bone density and symptoms: the Hingford Study. $J$ Bone Miner Res 1993;8:817-22.
5. Kaptoge S, Armbrecht G, Felsenberg D, et al.; EPOS Study Group. When should the doctor order a spine $\mathrm{x}$-ray? Identifying vertebral fractures for osteoporosis care: results from the European Prospective Osteoporosis Study (EPOS). J Bone Miner Res 2004;19:1982-93.

6. Gunnes M, Lehmann EH, Mellstrom D, et al. The relationship between anthropometric measurements and fractures in women. Bone 1996;19:407-13.

7. Vokes T, Bachman D, Baim S, et al. Vertebral fracture assessment: the 2005 ISCD official positions. J Clin Densitom 2006;9:37-46.

8. Krege JH, Siminoski K, Adachi JD, et al. A simple method for determining the probability a new vertebral fracture is present in postmenopausal women with osteoporosis. Osteoporos Int 2006; 17:379-86.

9. Siminoski K, Jiang G, Adachi JD, et al. The accuracy of height loss during prospective monitoring for detection of incident vertebral fractures. Osteoporos Int 2005;16:403-10.

10. Norton K, Whittingham N, Carter L, et al. Measurement techniques in anthropometry. In: Norton K, Olds T, editors. Anthropometrica. Sydney (Australia): University of New South Wales Press; 1996. p. 25-75.

11. Coles RJ, Clements DG, Evans WD. Measurements of height: practical considerations for the study of osteoporosis. Osteoporos Int 1994;4:353-6.

12. Cline MG, Merdith KE, Boyer JT, et al. Decline of height with age in adults in a general population sample: estimating maximum height and distinguishing birth cohort effects from actual loss of stature with aging. Hum Biol 1989;61:415-25.

13. Chandler PJ, Bock RD. Age changes in adult stature: trend estimation from mixed longitudinal data. Ann Hum Biol 1991;18:433-40.

14. Sahyoun NR, Maynard LM, Zhang XL, et al. Factors associated with errors in selfreported height and weight in older adults. J Nutr Health Aging 2008;12:108-15.

15. Kuczmarski MF, Kuczmarski RJ, Najjar M. Effects of age on validity of self-reported height, weight, and body mass index: findings from the Third National Health and Nutrition Examination Survey, 1988-1994. J Am Diet Assoc 2001;101:28-34.

16. Laakso V, Niemi PM, Grönroos M, et al. The worried young adult as a primary care patient. Fam Pract 2005;22:406-11.

17. Cooper C, Atkinson EJ, O'Fallon WM, et al. Incidence of clinically diagnosed vertebral fractures: a population-based study in Rochester, Minnesota, 1985-1989. J Bone Miner Res 1992;7:221-7.

18. Tobias JH, Hutchinson AP, Hunt LP, et al. Use of clinical risk factors to identify postmenopausal women with vertebral fractures. Osteoporos Int 2007;18:35-43.

19. Roux C, Priol G, Fechtenbaum J, et al. A clinical tool to determine the necessity of spine radiography in postmenopausal women with osteoporosis presenting with back pain. Ann Rheum Dis 2007;66:81-5.

20. Delmas PD, van de Langerijt L, Watts NB, et al.; IMPACT Study Group. Underdiagnosis of vertebral fractures is a worldwide problem: the IMPACT study. J Bone Miner Res 2005;20:557-63.

Correspondence to: Dr. Karine Briot, Service de rhumatologie, Hôpital Cochin, 27 rue Faubourg Saint-Jacques, 75014 Paris, France; karine.briot@cch.aphp.fr 